\title{
Managing back pain in pregnancy using a support garment: a randomised trial
}

\author{
SM Kalus, ${ }^{\text {a }}$ LH Kornman, ${ }^{\text {a JA Quinlivan }}{ }^{\text {b }}$ \\ ${ }^{\text {a }}$ Department of Obstetrics and Gynaecology, the University of Melbourne, Parkville, Victoria, Australia b Sydney School of Medicine, \\ The University of Notre Dame Australia, Broadway, New South Wales, Australia \\ Correspondence: Dr LH Kornman, Department of Obstetrics and Gynaecology, The University of Melbourne, The Royal Women's Hospital, \\ 132 Grattan Street, Carlton 3053 Victoria, Australia. Email louisehk@unimelb.edu.au
}

Accepted 28 August 2007. Published OnlineEarly 12 November 2007.

\begin{abstract}
Objective Large population studies have shown that low back pain affects about $50 \%$ of pregnant women. The aim of this study was to determine whether the use of the BellyBra ${ }^{\circledR}$ in pregnant women with back pain is associated with changes in assessments of pain severity, physical activity and satisfaction with life after 3 weeks of intervention compared with tubigrip, a more generic form of support.
\end{abstract}

Design Randomised controlled trial.

Setting A tertiary referral hospital in Australia.

Population Women between 20 and 36 weeks of pregnancy with lumbar back or posterior pelvic pain.

Methods Participants were randomised to the BellyBra ${ }^{\circledR}$ (the study device) or to tubigrip (the control) by means of computergenerated numbered, sealed, opaque envelopes.

Main outcome measures The primary outcomes were pain severity and physical activity, and the secondary outcome was satisfaction with life.
Results One hundred and fifteen women consented to participate in the trial. Mean visual analogue scale scores of pain severity decreased from 6.1 to 4.5 in the study device group $(P=0.001)$ and from 6.0 to 4.7 in the control group $(P=0.003)$. There was no significant difference between the groups in this outcome $(P=0.61)$. However, the study device group demonstrated a significantly greater reduction in Likert scale assessments of the impact of back pain on sleeping $(P=0.007)$, getting up from a sitting position $(P=0.02)$ and walking $(P=0.001)$ than the control group. There was also a significant reduction in the use of analgesic medication in the study group $(P=0.01)$.

Conclusion The BellyBra ${ }^{\circledR}$ and tubigrip were both associated with a reduction in the severity of pregnancy-related low back pain. The BellyBra ${ }^{\circledR}$ was more effective than tubigrip, however, in alleviating the impact of pain on a number of physical activities that constitute daily life.

Keywords Back pain, controlled trial, pelvic pain, pregnancy, support garment, therapy.

Please cite this paper as: Kalus S, Kornman L, Quinlivan J. Managing back pain in pregnancy using a support garment: a randomised trial. BJOG 2008;115:68-75.

\section{Introduction}

Studies have shown that approximately $50 \%$ of women experience low back pain during their pregnancy, and in many of these women, the pain is a severe problem compromising daily life. ${ }^{1-4}$ Back pain in pregnancy can cause substantial distress and disruption of function, interfering with sleep, work and capacity to carry out daily activities. In $25 \%$ of pregnant women with low back pain, the pain is very serious, while a further $8 \%$ have severe disability. ${ }^{3}$ This condition accounts for most of the sick leave among pregnant women and is also reported to reduce health-related quality of life. ${ }^{4}$ Indeed, a systematic review of physical therapy for pregnancyrelated back pain concluded that the prevention and treatment of this condition 'would have considerable implications for the women themselves and for society in terms of quality of life, public health costs and productivity, ${ }^{4}$ making this an area of great research need.

In one of the most comprehensive and reliable investigations of the prevalence of back pain in pregnancy, a prospective study of 855 women in Sweden in 1991, a 9-month period prevalence of $49 \%$ and a point prevalence of $22-28 \%$ were reported. ${ }^{2}$ This prevalence is higher than the expected lifetime prevalence of back pain of 20-25\% identified in nonpregnant women. ${ }^{5,6}$ However, the prevalence of pregnancy-related back pain has been reported to vary from 3.9 to $89.9 \%$ in 28 studies $^{1,2,7-31}$ included in a systematic review by Wu et al. ${ }^{3}$ of the clinical presentation, prevalence and terminology of 
pregnancy-related back pain. This is probably due to the variety of terms used to define pregnancy-related back pain and the unclear diagnostic criteria. Indeed, a recent editorial in the $B M J^{32}$ identified the need to classify back pain in pregnancy to understand better its origins and prevalence and to design more effective prophylactic and treatment interventions. The most significant attempt to define pregnancy-related back pain was made by Albert et al. ${ }^{33}$ in a study involving 1460 women in Denmark. They identified two broad categories: the first being pain arising from the area of the lumbar spine and the second being pelvic joint pain manifesting distal and lateral to the fifth lumbar vertebra. Pelvic, or sacroiliac, joint pain can be classified into pelvic girdle syndrome (pain in both sacroiliac joints and in the symphysis pubis), double-sided sacroiliac syndrome (with or without radiation in the sciatic distribution) or one-sided sacroiliac syndrome (again with or without radiation). Of these women, about one-half had posterior pelvic pain, one-third low back pain and one-sixth both conditions combined. $^{3}$

There are two systematic reviews of trials investigating treatments for back pain in pregnancy that can be used to guide current knowledge. A Cochrane review by Young and Jewell ${ }^{34}$ of three randomised controlled trials ${ }^{35-37}$ found that water gymnastics, acupuncture and use of a specially designed pillow were beneficial. The reviewers commented that physical therapy treatments may be more effective when given individually rather than in group sessions. The stability of the pelvic girdle is thought to be provided, in part, by the texture and shape of the sacroiliac cartilage (form closure) and, in part, by the compressive forces of muscles, ligaments and the thoracolumbar fascia (force closure) ${ }^{38}$ Research has shown that poor muscle function in the back and pelvis at the beginning of pregnancy is related to severe pain and disability throughout pregnancy. ${ }^{39}$ Indeed, many hypotheses correlate the pathogenesis of peripartum pelvic pain with decreased stability of the pelvic girdle, giving rise to a number of trials of physical therapy interventions aimed to improve the stability of the pelvic girdle and thereby relieve symptoms of pain and disability. The second systematic review by Stuge et al. ${ }^{4}$ considered nine randomised and nonrandomised trials ${ }^{35,37,38,40-45}$ of physical therapy and was unable to extend the conclusions of the Cochrane review due to the heterogeneity in the design of the trials.

The primary aims of the present study were to determine whether the use of the BellyBra ${ }^{\circledR}$ (study device; T\&J Designs Inc., Lakewood, CO, USA) during the second half of pregnancy is associated with changes in visual analogue scale (VAS) assessments of the severity of low back and posterior pelvic pain and in Likert scale scores of the influence of pain on predefined physical activities after 3 weeks of use. The secondary aims were to assess whether the study device is associated with changes in Satisfaction With Life Scale
(SLWS) scores and in the use of additional treatments for back pain, including analgesic medication. The use of tubigrip was implemented as a control.

\section{Methods}

A randomised controlled trial was conducted to evaluate the impact of the BellyBra ${ }^{\circledR}$ on back pain severity, associated functional impairment and satisfaction with life. The Human Research Ethics Committee at The Royal Women's Hospital, Melbourne, Australia, approved the trial, and it was formally registered with the Australian Clinical Trials Registry in September 2005 (registration number ACTRN012605000270617). The study was conducted using CONSORT criteria.

The BellyBra ${ }^{\circledR}$ (Figure 1), a nylon/spandex undergarment worn like a vest, has a one-way stretch panel across the thoracolumbar back that is designed to provide support and, assisted by the involvement of shoulder straps, to improve posture. A wide elastic band sits below the abdomen supporting the uterus and lifting weight off the pelvis. Tubigrip (Figure 2) is a more generic form of support and is common practice for the treatment of pregnant women with back pain at several Australian hospital sites. Tubigrip is worn as a double layer and extends from the mid-thoracic spine to the sacral spine and pelvis. The product available through the Department of Physiotherapy was Tubular-Form Natural.

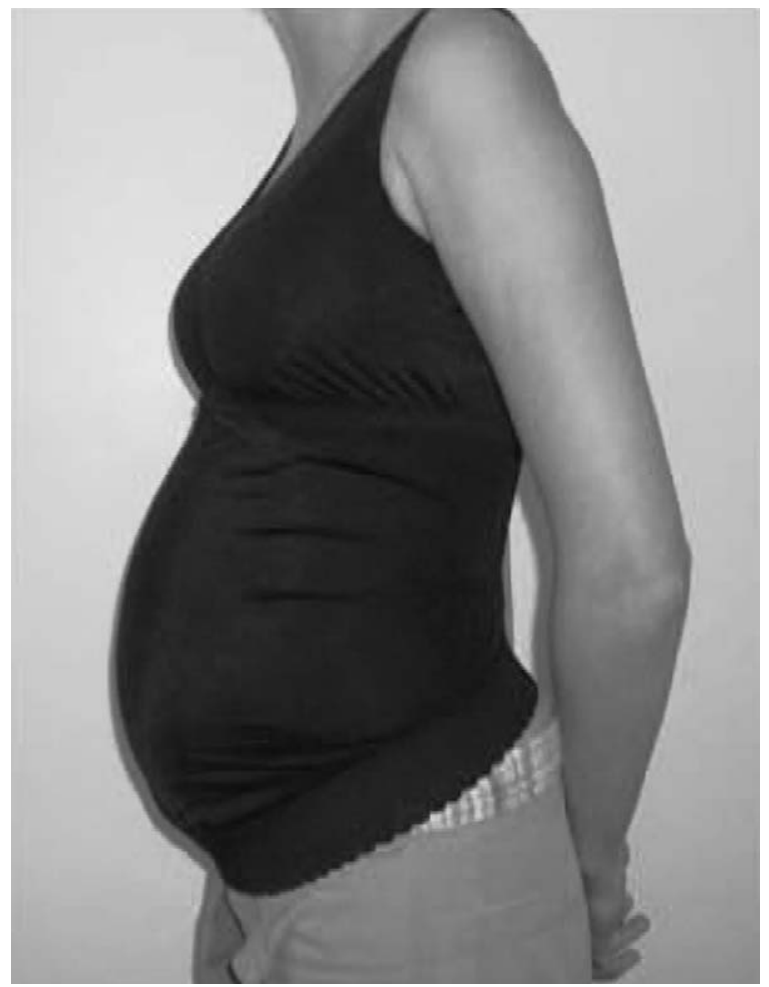

Figure 1. BellyBra ${ }^{\circledR}$ — the study device. 


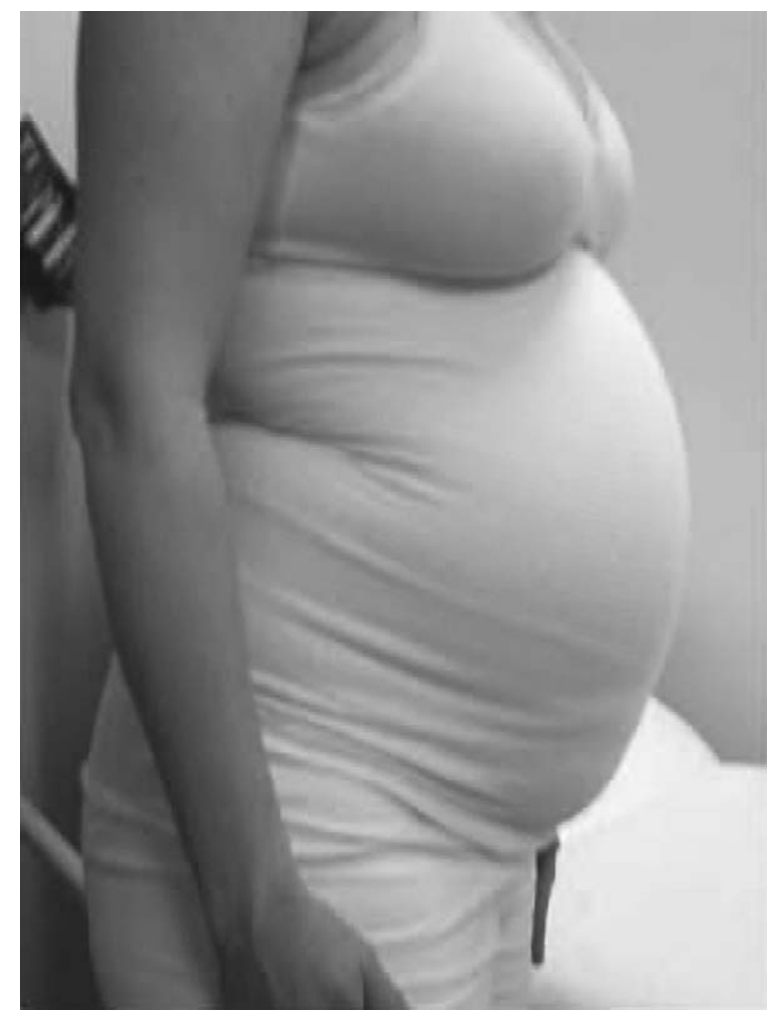

Figure 2. Tubigrip-the control.

Women between 20 and 36 weeks of pregnancy presenting at the antenatal clinics of The Royal Women's Hospital with lumbar back pain or posterior pelvic (sacroiliac joint) pain were invited to participate in the trial, which was carried out between July and December 2005. Diagnosis and classification of the pain was based on an oral history and on the patient's localisation of their pain on a visual back chart. Women with high back pain or symphysiolysis but with no concomitant lumbar back or posterior pelvic pain were excluded from the trial. Women were also excluded if their pregnancy was complicated or if they were non-English speaking. Following written informed consent, participants were randomised to the study device or to the control by means of computergenerated numbered, sealed, opaque envelopes. The women were fitted with the appropriate size of garment, instructed on how to wear the garment and informed that they could choose the frequency and duration of wear.

Upon enrolment, each participant completed a baseline questionnaire including background information, back pain history before and during the pregnancy and usage of treatments for pain. Participants rated the severity of their back pain on a VAS of 0 to 10 , where 0 denotes no pain at all and 10 the worst pain ever in life. There was an assessment on a Likert scale of 0 (never affected) to 10 (always affected) of the influence of pain on six defined kinds of physical activitiessleeping, getting up from a sitting position, sitting down, sitting, walking and working - and, overall, on their daily lives. There was an evaluation of life satisfaction using the SLWS.

The participants completed a follow-up questionnaire containing the same outcome measures of pain severity, physical activities and satisfaction with life at the completion of the 3 -week study period on a return visit to the antenatal clinic. The women were asked if they used any other treatments for their back pain during the trial (including analgesic medication), how much they wore the garment and their overall impression of its usefulness.

The primary outcomes were differences in VAS and Likert scale scores between the study device and control groups at follow up. The VAS has been used in previous studies investigating changes in pain and, specifically, in all the randomised trials of interventions for back pain in pregnancy included in or published since the Cochrane and systematic reviews. ${ }^{35-38,44,46,47}$ It is thus the most validated and reliable method of assessing the impact of the study device on pain severity. A Likert scale was used to assess the impact of pain on six important daily physical activities. This methodology has been used in a previous randomised trial evaluating acupuncture as a treatment of back pain in pregnancy. ${ }^{47}$ The secondary outcomes included the differences between the study device and control groups in SWLS scores at follow up. (The SWLS is a 5 -item questionnaire formulated by Diener et al..$^{48}$ in 1985 to measure life satisfaction as a cognitive-judgemental process.) The use of other treatments for back pain such as analgesic intake was also considered in the secondary outcomes.

It was calculated that a sample size of 37 women per cohort could detect a difference in VAS or Likert scale score of 1.0 between the study device and control groups, given a SD of 1.5 and a power of 0.80 . Allowing for a loss to follow up of $30 \%$, we planned to recruit 97 women into the study. The data collected were entered into a dataset and analysed using univariate and multivariate statistical techniques in Minitab. The data analysis was based on the intention-to-treat principle. Parametric data were analysed by comparing means of follow-up scores between the study device and control groups with the two-sample $t$ test, while the Mann-Whitney $U$ test was used for nonparametric data. The chi-square test or Fisher's exact test was used for analysis of discrete data. The Tukey-Kramer multiple comparison adjustment was used to calculate significance levels based upon the primary hypotheses in relation to VAS score and functional outcomes in between-group comparisons. A $P$ value of 0.03 is considered statistically significant.

\section{Results}

One hundred and fifteen women consented to participate in the trial. Fifty-five women were randomised to the study device, and 60 women were randomised to the control. 
Forty-six of the 55 women in the study device group and 48 of the 60 women in the control group completed the trial. Twenty-one participants in total were lost to follow up as they either delivered within the study period or did not attend follow-up appointments and could not be contacted for follow up. Figure 3 summarises the study protocol. There was no significant differences between the study device and control groups in baseline data: age, height, weight, parity or gestational age (28.2 versus 29.2 weeks $[P=0.28]$ for the device versus control).

There was no significant correlation between the baseline and follow-up VAS scores $(P=0.22-0.89)$, and the process of randomisation was effective in producing the baseline groups with equivalent demographic variable outcomes at randomisation. Therefore, the between-group difference at follow up was the most appropriate method to analyse primary outcome, as had been planned during the sample size calculations.

\section{Changes between groups}

Table 1 summarises the changes in outcomes between the study device and control groups. After 3 weeks, mean VAS scores of pain severity were not significantly different between the groups in this outcome at follow up $(P=0.61)$. The study device group had a significant reduction compared with the control group in the impact of back pain on sleeping (3.4 versus 4.8, respectively; $P=0.007)$, getting up from a sitting position (4.2 versus 5.4 , respectively; $P=0.02$ ) and walking (3.3 versus 5.3 , respectively; $P=0.001)$. However, there was no significant differences in sitting (4.0 versus $4.5 ; P=0.30$ ), sitting down (2.7 versus 3.7; $P=0.04)$ and overall impact (4.7 versus $5.6 ; P=0.07$ ) scores between the two cohorts. Follow-up SWLS scores did not differ significantly between the study device and control groups (23.1 versus 22.5 , respectively; $P=0.80$ ).

\section{Changes within groups}

Table 2 summarises the changes within the study device group. There was a significant reduction in VAS score (6.1-4.5; $P=$
0.001) and in the impact of back pain on sleeping, getting up from a sitting position, sitting down, sitting, walking, working and overall on daily activities (all $P<0.01$ ) over the study period. However, there was no significant change in satisfaction with life score $(25.0-23.1 ; P=0.24)$. Table 3 summarises the changes within the control group. There was a significant reduction in VAS score $(6.0-4.7 ; P=0.003)$ and in the impact of back pain on getting up from a sitting position, sitting down and working (all $P<0.03$ ) but no change in sleeping, sitting, walking and overall impact (all $P>0.05$ ). There was no significant change in satisfaction with life score $(25.5-22.5 ; P=0.09)$.

\section{Further outcomes}

Upon completion of the trial, 11 women $(23.9 \%)$ in the study device group and 23 women $(47.9 \%)$ in the control group reported that they had used other treatments for their back pain during the study period $(P=0.03)$. Three of the former and 14 of the latter indicated the use of analgesic medication $(P=0.01)$. Other methods of treatment included physiotherapy, acupuncture, massage, osteopathy, yoga, exercise, heat packs, pillows and bedrest. In the study device cohort, of the 46 participants, $44(95.7 \%)$ stated that they wore the garment at least once a week compared with 33 of the $48(68.8 \%)$ in the control cohort $(P=0.003)$. Regarding the participants' overall impression of the usefulness of the study device, $36(78.3 \%)$ stated that it was helpful or very helpful, $3(6.5 \%)$ neither helpful nor unhelpful and $7(15.2 \%)$ unhelpful or totally unhelpful. In the control group, 30 (62.5\%) women indicated that the tubigrip was helpful or very helpful, $6(12.5 \%)$ that it was neither helpful nor unhelpful and 12 (25\%) unhelpful or totally unhelpful.

\section{Discussion}

Pain severity decreased significantly over the 3-week study period in both the study device and control groups. The study device was not found to be more effective than the tubigrip in

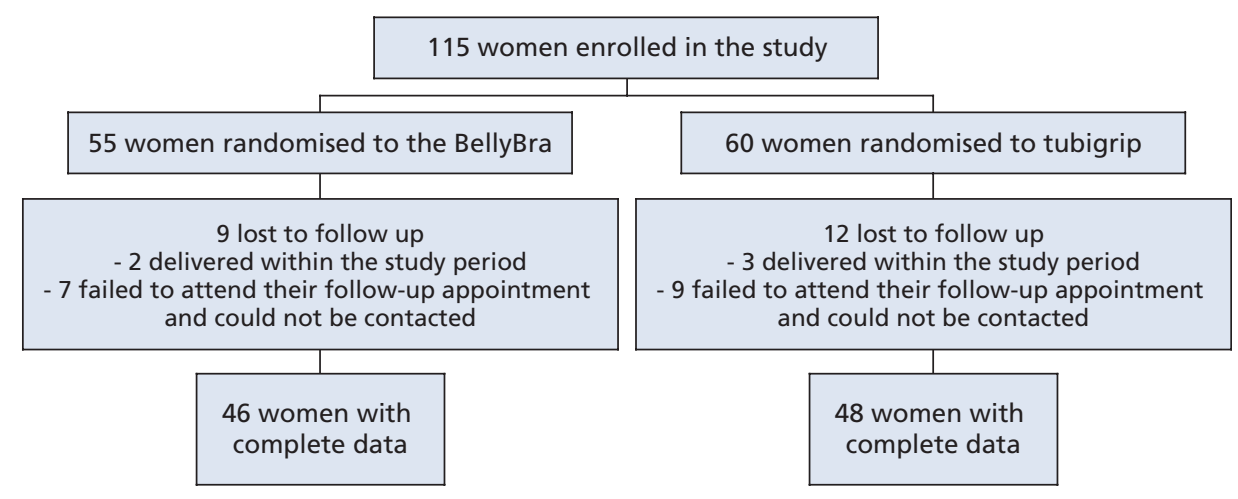

Figure 3. The study protocol. 
Table 1. Follow-up data-changes between groups

\begin{tabular}{|c|c|c|c|c|}
\hline & $\begin{array}{c}\text { BellyBra }{ }^{\circledR} \text { group } \\
\text { mean (SD) }\end{array}$ & $\begin{array}{l}\text { Tubigrip group } \\
\text { mean (SD) }\end{array}$ & $P$ value & $95 \% \mathrm{Cl}$ \\
\hline VAS & $4.5(2.6)$ & $4.7(2.3)$ & 0.61 & -1.25 to 0.74 \\
\hline \multicolumn{5}{|l|}{ Likert scale } \\
\hline Sleeping & $3.4(2.7)$ & $4.8(2.5)$ & 0.007 & -2.37 to -0.39 \\
\hline Getting up from a sitting position & $4.2(2.2)$ & $5.4(2.7)$ & 0.02 & -2.23 to -0.22 \\
\hline Sitting down & $2.7(2.2)$ & $3.7(2.4)$ & 0.04 & -1.92 to -0.05 \\
\hline Sitting & $4.0(2.3)$ & $4.5(2.5)$ & 0.30 & -1.52 to 0.48 \\
\hline Walking & $3.3(2.2)$ & $5.3(3.0)$ & 0.001 & -3.04 to -0.88 \\
\hline Working & $4.4(2.4)$ & $5.5(2.5)$ & 0.04 & -2.06 to -0.06 \\
\hline Overall impact on daily activities & $4.7(2.1)$ & $5.6(2.4)$ & 0.07 & -1.77 to -0.07 \\
\hline SWLS & $23.1(10.1)$ & $22.5(11.3)$ & 0.80 & -3.52 to 4.59 \\
\hline
\end{tabular}

All outcome measures are Likert scores on a continuous scale from 0 to 10 , except for the SWLS, which is a scale with a score from 0 to 35.48

relieving pain based on a VAS score. Whether this was because both the BellyBra ${ }^{\circledR}$ and tubigrip possess true efficacy or because one or both of the garments acted like a placebo is not known. However, the study device was significantly more effective than the control garment in reducing the impact of back pain on sleeping, getting up from a sitting position, walking and working. Furthermore, the study device significantly reduced the impact of back pain on all physical activities measured, whereas the control garment produced a level of significant improvement only for getting up from a sitting position, sitting down and working. This outcome must not be underestimated in its clinical relevance for pregnant women with back pain, for whom the condition is reported to be a severe problem compromising daily life in about onethird of cases. ${ }^{1,2,42}$ It would appear that the VAS, being an instantaneous measure of pain, did not discriminate on the functional impact of the pain. There was no significant changes in satisfaction with life either between or within the study device and control groups. This result is not surprising, given that the SWLS has been shown to have high internal consistency and high temporal stability and to be negatively correlated with clinical measures of distress, anxiety, depression and momentary mood. ${ }^{48}$ Life satisfaction and affective wellbeing are therefore not equivalent psychological constructs.

Significantly, fewer women in the study device group compared with the control group used other forms of treatment, including analgesic medication, during the period of the trial. This supports the finding that the study device is a more effective stand-alone treatment. Decreased analgesic use is one of the most significant differences between the study device and control groups ( 3 of 46 in the study device group versus 14 of 48 in the control group). Although this is a secondary outcome, it is an important difference given the

Table 2. Follow-up data—changes within the BellyBra ${ }^{\circledR}$ group

\begin{tabular}{|c|c|c|c|c|}
\hline & $\begin{array}{l}\text { Baseline } \\
\text { mean (SD) }\end{array}$ & $\begin{array}{l}\text { Follow-up } \\
\text { mean (SD) }\end{array}$ & $P$ value & $95 \% \mathrm{Cl}$ \\
\hline VAS & $6.1(2.2)$ & $4.5(2.6)$ & 0.001 & $0.64-2.575$ \\
\hline \multicolumn{5}{|l|}{ Likert scale } \\
\hline Sleeping & $6.1(2.4)$ & $3.4(2.7)$ & $<0.0001$ & $1.74-3.68$ \\
\hline Getting up from a sitting position & $6.6(2.7)$ & $4.2(2.2)$ & $<0.0001$ & $1.43-3.37$ \\
\hline Sitting down & $5.1(2.9)$ & $2.7(2.2)$ & $<0.0001$ & $1.34-3.37$ \\
\hline Sitting & $5.3(2.5)$ & $4.0(2.3)$ & 0.008 & $0.35-2.28$ \\
\hline Walking & $5.6(2.8)$ & $3.3(2.2)$ & $<0.0001$ & $1.27-3.27$ \\
\hline Working & $6.6(2.3)$ & $4.4(2.4)$ & $<0.0001$ & $1.21-3.11$ \\
\hline Overall impact on daily activities & $6.5(2.3)$ & $4.7(2.1)$ & $<0.0001$ & $0.87-2.62$ \\
\hline SWLS & $25.0(6.1)$ & $23.1(10.1)$ & 0.24 & -1.338 to 5.17 \\
\hline
\end{tabular}

All outcome measures are Likert scores on a continuous scale from 0 to 10 , except for the SWLS, which is a scale with a score from 0 to 35.48 
Table 3. Follow-up data-changes within the tubigrip group

\begin{tabular}{|c|c|c|c|c|}
\hline & $\begin{array}{l}\text { Baseline } \\
\text { mean (SD) }\end{array}$ & $\begin{array}{l}\text { Follow-up } \\
\text { mean (SD) }\end{array}$ & $P$ value & $95 \% \mathrm{Cl}$ \\
\hline VAS & $6.0(2.0)$ & $4.7(2.3)$ & 0.003 & $0.44-2.12$ \\
\hline \multicolumn{5}{|l|}{ Likert scale } \\
\hline Sleeping & $5.7(2.6)$ & $4.8(2.5)$ & 0.07 & -0.07 to 1.85 \\
\hline Getting up from a sitting position & $6.6(2.2)$ & $5.4(2.7)$ & 0.02 & $0.24-2.17$ \\
\hline Sitting down & $5.1(2.6)$ & $3.7(2.4)$ & 0.01 & $0.40-2.35$ \\
\hline Sitting & $5.1(2.7)$ & $4.5(2.5)$ & 0.23 & $-0.40-1.64$ \\
\hline Walking & $6.1(2.1)$ & $5.3(3.0)$ & 0.12 & -0.22 to 1.83 \\
\hline Working & $6.5(2.3)$ & $5.5(2.5)$ & 0.03 & $0.13-1.99$ \\
\hline Overall impact on daily activities & $6.4(1.7)$ & $5.6(2.4)$ & 0.06 & -0.03 to 1.92 \\
\hline SWLS & $25.5(6.4)$ & $22.5(11.3)$ & 0.09 & -0.44 to 6.39 \\
\hline
\end{tabular}

All outcome measures are Likert scores on a continuous scale from 0 to 10 , except for the SWLS, which is a scale with a score from 0 to 35.48

accumulation of data suggesting long-term negative consequences of analgesic drug use in pregnancy, on the offspring. ${ }^{49-51}$ There was also a significant difference between cohorts in how frequently the participants wore the garments, with $95.7 \%$ of the study device group wearing the garment at least once a week compared with $70.2 \%$ of the control group.

In the design of the trial, it was thought that tubigrip would be used as the control to eliminate an unbalanced placebo effect in the intervention cohort and a disappointment factor in the control cohort, whereby findings of significant efficacy could have been attributed to a placebo effect rather than to any real value of the study device itself. Thus, the BellyBra ${ }^{\circledR}$ was compared with tubigrip, a more generic form of support. However, tubigrip significantly reduced back pain severity and impact on certain physical activities. Where there was no significant improvement, tubigrip nevertheless appeared to halt the expected worsening of back pain over the pregnancy. Given that tubigrip has never before been subjected to any formal evaluation, it cannot be known from this study whether the observed outcomes of using tubigrip were due to a placebo effect or due to true efficacy. Nor can we know the size of the effect of the study device over no treatment. Perhaps, a true placebo, such as a camisole or singlet, with merely a perceived efficacy among participants would have been a more accurate control. This is a limitation of our study and a question that requires further research. It does not, however, detract from the evaluated benefit of the BellyBra ${ }^{\circledR}$ over tubigrip in a number of areas of functional status.

There was a relatively high loss to follow up (21 women in total). Five women delivered within the 3-week period. Of the remaining 16 , some had moved away and others were unable to be interviewed at a clinic appointment 3 weeks later. All these women were sent a follow-up questionnaire at their given address (with a reply-paid envelope). If this did not lead to a reply, attempts were then made to contact them by phone. Only when all these attempts were unsuccessful, they were recorded as 'lost to follow up'. For those who delivered within our hospital and for whom data were available on the hospital electronic discharge system, there did not appear to be any distinguishing characteristics between the defaulters and those women who had completed their questionnaire.

The 3-week duration of the trial limits the scope of the study insofar as we could not evaluate the long-term effects of the study device, including its impact on pain and activity over the entire pregnancy, delivery and postpartum back pain and recovery. In most cases, women with low back pain during pregnancy recover within 1-3 months postpartum. ${ }^{1,2,23}$ However, studies have found that recovery of low back and pelvic pain after pregnancy is often incomplete and may persist for years after childbirth. ${ }^{8,52}$ Moreover, pregnancy is a major risk factor in a primary care back pain population. Indeed, $10-20 \%$ of women with chronic low back pain associate its initial presentation with pregnancy. ${ }^{49}$ Therefore, while it was not possible in the time frame of our study, it is important to evaluate interventions for pregnancy-related back pain also in terms of long-term effects. Furthermore, although this study assessed the impact of the study device on many activities of daily life, including work, it did not measure whether the study device reduced days of sick leave. We anticipated that statistical power would not have been sufficient for analysis of this outcome as some of the women were not in paid employment. Cohort size was also not sufficient for statistical analysis of the impact of the study device or control garment on low back pain compared with posterior pelvic pain over the study period. Given that the aetiology of back pain in pregnancy is poorly understood, clearly an important question is whether treatment interventions, such 
as the BellyBra ${ }^{\circledR}$, have different effects and degrees of benefit on different types of back pain. It should be noted that the limitations discussed do not affect the accuracy or clinical relevance of our evaluation of the study device but rather indicate that there is scope for further investigation of types of back pain and methods of treatment.

\section{Conclusion}

The present study is the first to formally evaluate the use of a lumbopelvic support garment to treat low back and posterior pelvic pain in pregnant women. Further research is needed to determine whether tubigrip has true efficacy or whether the observed outcomes are due to a placebo effect alone. The study device (BellyBra ${ }^{\circledR}$ ) can be recommended as a method of treatment for women presenting with low back or posterior pelvic pain during pregnancy.

\section{Conflict of interest}

The distributors of the BellyBra provided their garments free of charge for use in this study but otherwise played no role in the study design, conduct, analysis or preparation of this manuscript. The authors have received no financial remuneration from the distributors.

\section{Acknowledgements}

The Department of Obstetrics and Gynaecology at The University of Melbourne acknowledges the assistance of Fertile Mind Pty Ltd in providing the BellyBras that were used in the trial. The authors thank Dr Ritu Mogra for her assistance in the early stages of this trial. No author contributing to this study received any funding or support for the study.

\section{References}

1 Kristiansson P, Svardsudd K, von Schoultz B. Back pain during pregnancy: a prospective study. Spine 1996;21:702-9.

2 Ostgaard HC, Andersson GB, Karlsson K. Prevalence of back pain in pregnancy. Spine 1991;16:549-52.

3 Wu WH, Meijer OG, Uegaki K, Mens JM, van Dieen JH, Wuisman PI, et al. Pregnancy-related pelvic girdle pain (PPP), I: terminology, clinical presentation, and prevalence. Eur Spine J 2004;13:575-89.

4 Stuge B, Hilde G, Vollestad N. Physical therapy for pregnancy-related low back and pelvic pain: a systematic review. Acta Obstet Gynecol Scand 2003;82:983-90.

5 Biering-Sorensen F. Low back trouble in a general population of 30-, 40-, 50-, and 60-year-old men and women. Study design, representativeness and basic results. Dan Med Bull 1982;29:289-99.

6 Neuhauser H, Ellert U, Ziese T. [Chronic back pain in the general population in Germany 2002/2003: prevalence and highly affected population groups]. Gesundheitswesen 2005;67:685-93.
7 Albert H, Godskesen M, Westergaard J. Evaluation of clinical tests used in classification procedures in pregnancy-related pelvic joint pain. Eur Spine J 2000;9:161-6.

8 Albert H, Godskesen M, Westergaard J. Prognosis in four syndromes of pregnancy-related pelvic pain. Acta Obstet Gynecol Scand 2001;80: 505-10.

9 Berg G, Hammar M, Moller-Nielsen J, Linden U, Thorblad J. Low back pain during pregnancy. Obstet Gynecol 1988;71:71-5.

10 Bjorklund K, Bergstrom S. Is pelvic pain in pregnancy a welfare complaint? Acta Obstet Gynecol Scand 2000;79:24-30.

11 Endresen EH. Pelvic pain and low back pain in pregnant women-an epidemiological study. Scand J Rheumatol 1995;24:135-41.

12 Farbrot E. The relationship of the effect and pain of pregnancy to the anatomy of the pelvis. Acta Radiol 1952;38:403-19.

13 Fast A, Shapiro D, Ducommun EJ, Friedmann LW, Bouklas T, Floman Y. Low-back pain in pregnancy. Spine 1987;12:368-71.

14 Fast A, Weiss L, Ducommun EJ, Medina E, Butler JG. Low-back pain in pregnancy. Abdominal muscles, sit-up performance, and back pain. Spine 1990;15:28-30.

15 Fast A, Weiss L, Parikh S, Hertz G. Night backache in pregnancy. Hypothetical pathophysiological mechanisms. Am J Phys Med Rehabil 1989; 68:227-9.

16 Fung BK, Kwong CM, Ho ES. Low back pain of women during pregnancy in the mountainous district of central Taiwan. Zhonghua Yi Xue Za Zhi (Taipei) 1993;51:103-6.

17 Howell CJ, Kidd C, Roberts W, Upton P, Lucking L, Jones PW, et al. $A$ randomised controlled trial of epidural compared with non-epidural analgesia in labour. BJOG 2001;108:27-33.

18 Larsen EC, Wilken-Jensen C, Hansen A, Jensen DV, Johansen S, Minck $\mathrm{H}$, et al. Symptom-giving pelvic girdle relaxation in pregnancy. I: prevalence and risk factors. Acta Obstet Gynecol Scand 1999;78: 105-10.

19 Macarthur A, Macarthur C, Weeks S. Epidural anaesthesia and low back pain after delivery: a prospective cohort study. BMJ 1995;311: 1336-9.

20 Mantle MJ, Greenwood RM, Currey HL. Backache in pregnancy. Rheumatol Rehabil 1977;16:95-101.

21 Melzack R, Belanger E. Labour pain: correlations with menstrual pain and acute low-back pain before and during pregnancy. Pain 1989; 36:225-9.

22 Noren L, Ostgaard S, Johansson G, Ostgaard HC. Lumbar back and posterior pelvic pain during pregnancy: a 3-year follow-up. Eur Spine J 2002;11:267-71.

23 Orvieto R, Achiron A, Ben-Rafael Z, Gelernter I, Achiron R. Low-back pain of pregnancy. Acta Obstet Gynecol Scand 1994;73:209-14.

24 Ostgaard HC, Roos-Hansson E, Zetherstrom G. Regression of back and posterior pelvic pain after pregnancy. Spine 1996;21:2777-80.

25 Ostgaard HC, Zetherstrom G, Roos-Hansson E. The posterior pelvic pain provocation test in pregnant women. Eur Spine J 1994;3:258-60.

26 Padua L, Padua R, Bondi R, Ceccarelli E, Caliandro P, D'Amico P, et al. Patient-oriented assessment of back pain in pregnancy. Eur Spine $J$ 2002;11:272-5.

27 Russell R, Dundas R, Reynolds F. Long term backache after childbirth: prospective search for causative factors. BMJ 1996;312:1384-8.

28 Sturesson B, Uden G, Uden A. Pain pattern in pregnancy and "catching" of the leg in pregnant women with posterior pelvic pain. Spine 1997;22:1880-3; discussion 1884.

29 Svensson HO, Andersson GB, Hagstad A, Jansson PO. The relationship of low-back pain to pregnancy and gynecologic factors. Spine 1990; 15:371-5.

30 van Dongen PW, de Boer M, Lemmens WA, Theron GB. Hypermobility and peripartum pelvic pain syndrome in pregnant South African women. Eur J Obstet Gynecol Reprod Biol 1999;84:77-82. 
31 Wergeland E, Strand K. Work pace control and pregnancy health in a population-based sample of employed women in Norway. Scand J Work Environ Health 1998;24:206-12.

32 Stones RW, Vits K. Pelvic girdle pain in pregnancy. BMJ 2005;331:249-50.

33 Albert HB, Godskesen M, Westergaard JG. Incidence of four syndromes of pregnancy-related pelvic joint pain. Spine 2002;27:2831-4.

34 Young G, Jewell D. Interventions for preventing and treating pelvic and back pain in pregnancy. Cochrane Database Syst Rev 2002; CD001139. DOI: 10.1002/14651858.CD001139.

35 Wedenberg K, Moen B, Norling A. A prospective randomized study comparing acupuncture with physiotherapy for low-back and pelvic pain in pregnancy. Acta Obstet Gynecol Scand 2000;79:331-5.

36 Thomas IL, Nicklin J, Pollock H, Faulkner K. Evaluation of a maternity cushion (Ozzlo pillow) for backache and insomnia in late pregnancy. Aust N Z J Obstet Gynaecol 1989;29:133-8.

37 Kihlstrand M, Stenman B, Nilsson S, Axelsson O. Water-gymnastics reduced the intensity of back/low back pain in pregnant women. Acta Obstet Gynecol Scand 1999;78:180-5.

38 Mens JM, Snijders CJ, Stam HJ. Diagonal trunk muscle exercises in peripartum pelvic pain: a randomized clinical trial. Phys Ther 2000; 80:1164-73.

39 Sihvonen $\mathrm{T}$, Huttunen $\mathrm{M}$, Makkonen $\mathrm{M}$, Airaksinen O. Functional changes in back muscle activity correlate with pain intensity and prediction of low back pain during pregnancy. Arch Phys Med Rehabil 1998;79:1210-12.

40 Dumas GA, Reid JG, Wolfe LA, Griffin MP, McGrath MJ. Exercise, posture, and back pain during pregnancy. Clin Biomech (Bristol, Avon) 1995;10:104-9.

41 Field T, Hernandez-Reif M, Hart S, Theakston H, Schanberg S, Kuhn C. Pregnant women benefit from massage therapy. J Psychosom Obstet Gynaecol 1999;20:31-8.

42 Mantle MJ, Holmes J, Currey HL. Backache in pregnancy II: prophylactic influence of back care classes. Rheumatol Rehabil 1981;20: 227-32.
43 Noren L, Ostgaard S, Nielsen TF, Ostgaard HC. Reduction of sick leave for lumbar back and posterior pelvic pain in pregnancy. Spine 1997; 22:2157-60.

44 Nilsson-Wikmar L, Holm K, Oijerstedt R, Harms-Ringdahl K. Effect of three different physical therapy treatments on pain and activity in pregnant women with pelvic girdle pain: a randomized clinical trial with 3, 6, and 12 months follow-up postpartum. Spine 2005;30: 850-6.

45 Ostgaard HC, Zetherstrom G, Roos-Hansson E, Svanberg B. Reduction of back and posterior pelvic pain in pregnancy. Spine 1994;19: 894-900.

46 Elden $H$, Ladfors L, Olsen MF, Ostgaard HC, Hagberg H. Effects of acupuncture and stabilising exercises as adjunct to standard treatment in pregnant women with pelvic girdle pain: randomised single blind controlled trial. BMJ 2005;330:761.

47 Kvorning N, Holmberg C, Grennert L, Aberg A, Akeson J. Acupuncture relieves pelvic and low-back pain in late pregnancy. Acta Obstet Gynecol Scand 2004;83:246-50.

48 Diener E, Emmons RA, Larsen RJ, Griffin S. The Satisfaction With Life Scale. J Pers Assess 1985;49:71-5.

49 Sorensen HJ, Mortensen EL, Reinisch JM, Mednick SA. Association between prenatal exposure to analgesics and risk of schizophrenia. Br J Psychiatry 2004;185:366-71.

50 Gilman EA, Wilson LM, Kneale GW, Waterhouse JA. Childhood cancers and their association with pregnancy drugs and illnesses. Paediatr Perinat Epidemiol 1989;3:66-96.

51 Shaheen SO, Newson RB, Henderson AJ, Headley JE, Stratton FD, Jones RW, et al. Prenatal paracetamol exposure and risk of asthma and elevated immunoglobulin E in childhood. Clin Exp Allergy 2005; $35: 700-2$.

52 Stuge B, Veierod MB, Laerum E, Vollestad N. The efficacy of a treatment program focusing on specific stabilizing exercises for pelvic girdle pain after pregnancy: a two-year follow-up of a randomized clinical trial. Spine 2004;29:E197-203. 